\title{
OS AQUÍFEROS QUE CONTRIBUEM NO ABASTECIMENTO DA CIDADE DE CURITIBA-PARANÁ
}

\author{
Ernani Francisco da Rosa Filho ${ }^{1}$ \\ Eduardo Chemas Hindi ${ }^{1}$ \\ Leandson Roberto F. de Lucena ${ }^{2}$
}

\begin{abstract}
RESUMO
No Estado do Paraná as investigações hidrogeológicas desenvolvidas de forma sistemática tiveram início no ano de 1973. Estudos geológicos desenvolvidos na Região Metropolitana de Curitiba e as informações contidas no banco de dados da Superintendencia dos Recursos Hídricos e Saneamento ambiental (SUDERHSA), bem como nas empresas de perfurações de poços tubulares, permitem distinguir três aqüíferos na região, a saber: o Embasamento cristalino, o Guabirotuba e o Karst. O primeiro e o segundo são utilizados para abastecer condomínios e postos de serviços em geral, enquanto o Karst é utilizado para abastecimento público. Estima-se que o volume anual produzido pelo embasamento cristalino é de aproximadamente $5.733 .234 \mathrm{~m}^{3}$, o que permite o abastecimento de mais ou menos 76.000 pessoas. A vazão média dos poços perfurados no aquífero cárstico é de aproximadamente $160.000 \mathrm{~L} / \mathrm{h}$, correspondendo a uma produção da ordem de 9.000 .000 $\mathrm{m}^{3} / a n$. A população atualmente abastecida com águas deste aquífero gira em torno de 185.515 habitantes. O aqüífero Guabirotuba, exceção da região nordeste de Curitiba, ocorre sob a forma de lentes de arcósios. As vazões variam de $5.000 \mathrm{~L} / \mathrm{h} /$ poço a $80.000 \mathrm{~L} / \mathrm{h} /$ poço.
\end{abstract}

Palavras chaves: água subterrânea; poços tubulares; abastecimento público

\section{Introdução}

As destinações mais tradicionais para a água são o abastecimento público e industrial e a irrigação. A demanda mundial de água para o ano 2000 é da ordem de $18.700 \mathrm{~km}^{3} / \mathrm{ano}$, sendo que $600 \mathrm{~km}^{3} / \mathrm{ano}$ serão necessários apenas para o consumo humano, $9.000 \mathrm{~km}^{3} /$ ano à diluição de esgotos, $7.000 \mathrm{~km}^{3} /$ ano à irrigação, 1.700 $\mathrm{km}^{3} / \mathrm{ano}$ às indústrias e $400 \mathrm{~km}^{3} / \mathrm{ano}$ para outras finalidades (REBOUÇAS, 1980). Estima-se, em nível mundial, que o percentual atual da população que consome exclusivamente água subterrânea é superior a $50 \%$ e que aproximadamente 90 milhões de hectares têm sido irrigados com águas do subsolo (SOLLEY et al., 1993). A utilização racional deste recurso é considerada como a base da riqueza das regiões oeste e central dos Estados Unidos. Mais ou menos 75\% dos sistemas de abastecimento público da Europa são atendidos com águas subterrâneas, sendo que o percentual médio da população européia atendida com este manancial gira em torno de 85\% (OECD, 1989).

No Brasil, cerca de $61 \%$ da população se auto-abastece com água subterrânea, sendo $43 \%$ por meio de poços tubulares, $12 \%$ por meio de fontes e $6 \%$ através de poços cacimbas (IBGE, 1991). É estimado que cerca de $75 \%$ das cidades do Estado de São Paulo e mais ou menos 90\% das cidades paranaenses são abastecidas

\footnotetext{
${ }^{1}$ UFPR - Laboratório de Pesquisas Hidrogeológicas; Centro Politécnico - Jardim das Américas, CEP 81.5321-990 Curitiba-PR. Tel/Fax: (41) 267-7910; ernani@setuva.geologia.ufpr.br

2 Doutorando em Geologia Ambiental - Dpto. Geologia - UFPR, Centro Politécnico - Jd. das Américas - 81531-990 - Curitiba-PR. Fone/Fax: (41) 267-7910.
} 
com águas subterrâneas (REBOUÇAS, 1996).

O consumo de água per capita varia em função de fatores os mais variados, mesmo numa região homogênea. Para efeito de entendimento do que a vazão produzida por um poço pode representar ao abastecimento da população, considera-se como demanda por ligação residencial nas cidades paranaenses um valor da ordem de 1.000 L/dia. A título de exemplo, um poço que produz apenas $1.000 \mathrm{~L} / \mathrm{h}$, tem capacidade para abastecer em torno de 120 pessoas, sendo que um outro bombeado a uma taxa de $100.000 \mathrm{~L} / \mathrm{h}$ ou $28 \mathrm{~L} / \mathrm{s}$ pode abastecer uma cidade com uma população de aproximadamente 12.000 pessoas.

\subsection{Histórico sobre o abastecimento de água de Curitiba}

A denominada Grande Curitiba compreende as cidades de Almirante Tamandaré, Colombo e Campina Grande do Sul, localizadas na bacia do Ribeira, bem como as cidades de Araucária, Curitiba, Piraquara, São José dos Pinhais e Pinhais, na bacia do Iguaçu, além de Quatro Barras, estando esta localizada no divisor de águas das bacias hidrográficas mencionadas. A população total atual destas cidades atinge cerca de 5.156.500 habitantes. A demanda total de água da população da Região Metropolitana de Curitiba (RMC), que atualmente conta com uma população de aproximadamente 2,6 milhões de habitantes, é em torno de 6.400 L/s. O consumo doméstico estimado per capita varia entre 180 a $200 \mathrm{~L} /$ dia, sendo que as indústrias consomem cerca de 200 L/s (DALARMI, 1995).

Os mananciais captados na Serra do Mar, da ordem de $120 \mathrm{~L} / \mathrm{s}$, foram suficientes para abastecer Curitiba até o ano de 1945; nessa época a população era de apenas 150.000 pessoas. Com o aumento da população da ordem de quatro vezes em apenas 20 anos, o abastecimento passou a ser feito através da captação do rio Iraí, com uma produção máxima de $800 \mathrm{~L} / \mathrm{s}$, e através do rio Iguaçu, com mais $3.000 \mathrm{~L} / \mathrm{s}$. No final da década de 80 , foi concluída a barragem do Passaúna, a qual possui uma capacidade nominal de $2.000 \mathrm{~L} / \mathrm{s}$. O total disponível atualmente corresponde a $5.800 \mathrm{~L} / \mathrm{s}$.

\subsection{Sistema atual de abastecimento de água da Região Metropolitana de Curitiba}

O abastecimento de água de Curitiba é feito atualmente através da captação do rio Passaúna e do sistema Alto Iguaçu.

Na parte oeste da cidade de Curitiba, a captação é feita no rio Passaúna cuja capacidade operacional do sistema varia entre 1.300 a $1.700 \mathrm{~L} / \mathrm{s}$. A área da bacia hidrográfica do Passaúna, até o local da barragem, corresponde a $143 \mathrm{~km}^{2}$. Destaquese que é na sua porção norte que está localizado o aterro sanitário Lamenha Pequena (desativado no final da década 80).

Na parte leste de Curitiba, a captação é feita no rio Iraí, onde a produção máxima é limitada a $800 \mathrm{~L} / \mathrm{s}$, e no rio Iguaçu, cuja produção é da ordem de 3.000 L/s. O total disponível atualmente (Passaúna + Iraí + Iguaçu) corresponde a uma vazão de 5.800 L/s. O atual deficit é, portanto, da ordem de 600 L/s. Este valor deixa sem água uma população de aproximadamente $320 \mathrm{mil}$ pessoas durante 60 horas por semana, o que eqüivale a dois dias e meio por semana ou dez dias durante um mês.

\subsection{Proposta de ampliação dos sistemas de captação segundo o Plano Diretor de Curitiba}

A partir de procedimentos baseados na viabilização da potabilização de efluentes do rio Iguaçu, é proposto por DALARMI (1995) a construção de mais cinco barragens para captação dos seguintes rios: Iraí, Piraquara, Pequeno, Miringuava e Cotia/Despique. Segundo este autor, os sistemas de produção de água estariam representados por três sistemas, a saber: Iraí (barragens Iraí, Piraquara II e Pequeno), Miringuava (barragem no rio Miringuava) e Cotia/Despique (barragens no rio Cotia/Despique). A previsão de produção destes sistemas até o final do ano 2020 é de $12,74 \mathrm{~m}^{3} / \mathrm{s}$, incluindo a "vazão emergencial" de $600 \mathrm{~L} / \mathrm{s}$ do aqüífero cárstico que deveria ter entrado em operação em 1995. A localização das barragens, pode ser visualizada na Figura 1.

A interpretação da evolução desse plano é que as barragens Iraí, Piraquara e Pequeno deverão estar produzindo em torno de $9 \mathrm{~m}^{3} / \mathrm{s}$ no ano 2006. Esta produção inclui a vazão do atual sistema de abastecimento de Curitiba. Com o funcionamento da barragem Miringuava, no ano 2013, a produção do sistema deverá aumentar para $10,7 \mathrm{~m}^{3} / \mathrm{s}$, e com o acréscimo a ser obtido com a barragem do Cotia/Despique, no ano 2020, a produção 
atingirá $12,74 \mathrm{~m}^{3} / \mathrm{s}$. Partindo do pressuposto que a partir do ano 2000 o consumo per capita será em torno de 190 L/dia, a produção máxima prevista para este sistema, de 12,74 $\mathrm{m}^{3} / \mathrm{s}$, poderá abastecer uma população de aproximadamente 5.800 .000 habitantes.

Os estudos desenvolvidos pela JICA Japan International Cooperation Agency (1995) propõem a construção das seguintes barragens: Piraquara II $\left(0,7 \mathrm{~m}^{3} / \mathrm{s}\right.$; US $\$ 18$ milhões de dólares), Cotia/Despique $\left(1,2 \mathrm{~m}^{3} / \mathrm{s}\right.$; US\$ 36 milhões de dólares), Alto Miringuava $\left(1 \mathrm{~m}^{3} / \mathrm{s} ;\right.$ US $\$ 30,5$ milhões), Onças $\left(0,6 \mathrm{~m}^{3} / \mathrm{s}\right.$; US\$ 18,6 milhões), Pequeno (0,9 $\mathrm{m}^{3} / \mathrm{s} ; 30,6$ milhões) e Faxinal $\left(0,5 \mathrm{~m}^{3} / \mathrm{s}\right.$; US\$ 21,5 milhões). A produção destas barragens e os custos de construção correspondem a $6 \mathrm{~m}^{3} / \mathrm{s}$ e 195 milhões de dólares, respectivamente. É igualmente proposto pela JICA (1995) a perfuração de 28 poços tubulares com profundidade de oitenta metros/unidade para captar uma vazão de $1,3 \mathrm{~m}^{3} / \mathrm{s}$ (aqüífero cárstico), a um custo estimado em 40 milhões de dólares.

O resumo do orçamento do Projeto Karst - Sítio Colombo, elaborado pela Sanepar, destaca as seguintes partes do sistema: captação (US\$ 575.931,00), adução de água bruta (US\$ $1319.280,00)$, estação de tratamento de água (US\$ 1.442.521,00), estação elevatória de água tratada (US\$ 1.195.995,00), adutora de água tratada (US\$ $516.806,00)$, reservatório Colombo Sede (US\$ $470.239,00)$, adutora de água tratada por gravidade (US\$ 5.200.000,00), centro de reservação Colombo estrada/São Gabriel (US\$ 505.942,00), centro de reservação vila Guarani (US\$ 1.845.208,00), centro de reservação Santa Cândida (US\$ $531.000,00$ ), rede de distribuição (US\$ $5.974 .872,00$ ) e itens especiais (US\$ 1.367.134,00). O valor total está orçado em torno de US\$20 944.933.

As projeções de crescimento e da demanda de água em cidades com peculiaridades como as que tem Curitiba é tarefa cujos resultados são muito imprecisos. O índice de ocupação de Curitiba, respectivo ao período de 1945 a 1980, foi da ordem de $6,8 \%$. Para admitir uma população de 5.800 .000 habitantes no ano 2020, o índice de crescimento a partir de 1997 deverá ficar restrito a 2,2\%. Qualquer valor superior a este representará, sem dúvida, deficit no abastecimento de água da cidade. Tornam-se imprescindíveis, por esta razão, investimentos na busca de novas alternativas para 0 abastecimento de água da Região Metropolitana de Curitiba, a exemplo dos mananciais subterrâneos armazenados nas rochas carstificadas da Formação Capiru, nas lentes e camadas arcoseanas da Formação Guabirotuba, no embasamento cristalino e nos aluviões do rio Iguaçu.

\section{Os Principais Aquíferos da Região Metropolitana de Curitiba (RMC)}

O presente trabalho não tem o objetivo de tecer considerações aprofundadas a respeito dos parâmetros hidráulicos e hidroquímicos dos aquíferos que ocorrem na RMC. Os dados apresentados referem-se apenas às vazões dos poços utilizados nos sistemas de abastecimento público e aos teores dos elementos químicos presentes nas águas, destacando a adequabilidade de uso ao consumo humano.

\subsection{Aquífero Embasamento Cristalino}

Os migmatitos, bem como as rochas granitóides e gnáissicas, representam as unidades aqüíferas do embasamento cristalino da Região Metropolitana de Curitiba (RMC). Estas rochas ocupam uma área de aproximadamente $7.500 \mathrm{~km}^{2}$, no Primeiro Planalto Parananense, numa faixa que abrange o município de Curitiba, parte dos municípios de Araucária, Almirante Tamandaré, Campina Grande do Sul, Campo Largo, Colombo, Piraquara, Quatro Barras e São José dos Pinhais.

A taxa média anual de chuvas na região é em torno de $1.500 \mathrm{~mm}$. A infiltração e a percolação das águas se faz através de geoestruturas em geral, a exemplo de diáclases e falhas geológicas. O manto de alteração das rochas e os sedimentos quaternários, encontram-se saturados com água e funcionam como reguladores da recarga dos aquíferos durante todo o ano. As estruturas através das quais circulam as águas distribuem-se preferencialmente entre 60 e $150 \mathrm{~m}$ de profundidade. SALAMUNI (1981) menciona a existência de fraturamentos de interesse hidrogeológico localizados aos $335 \mathrm{~m}$ de profundidade. A vazão média deste aqüífero é da ordem de $13.000 \mathrm{~L} / \mathrm{h} /$ poço e os valores máximos de capacidades específicas raramente superam $300 \mathrm{~L} / \mathrm{h} / \mathrm{m}$. 


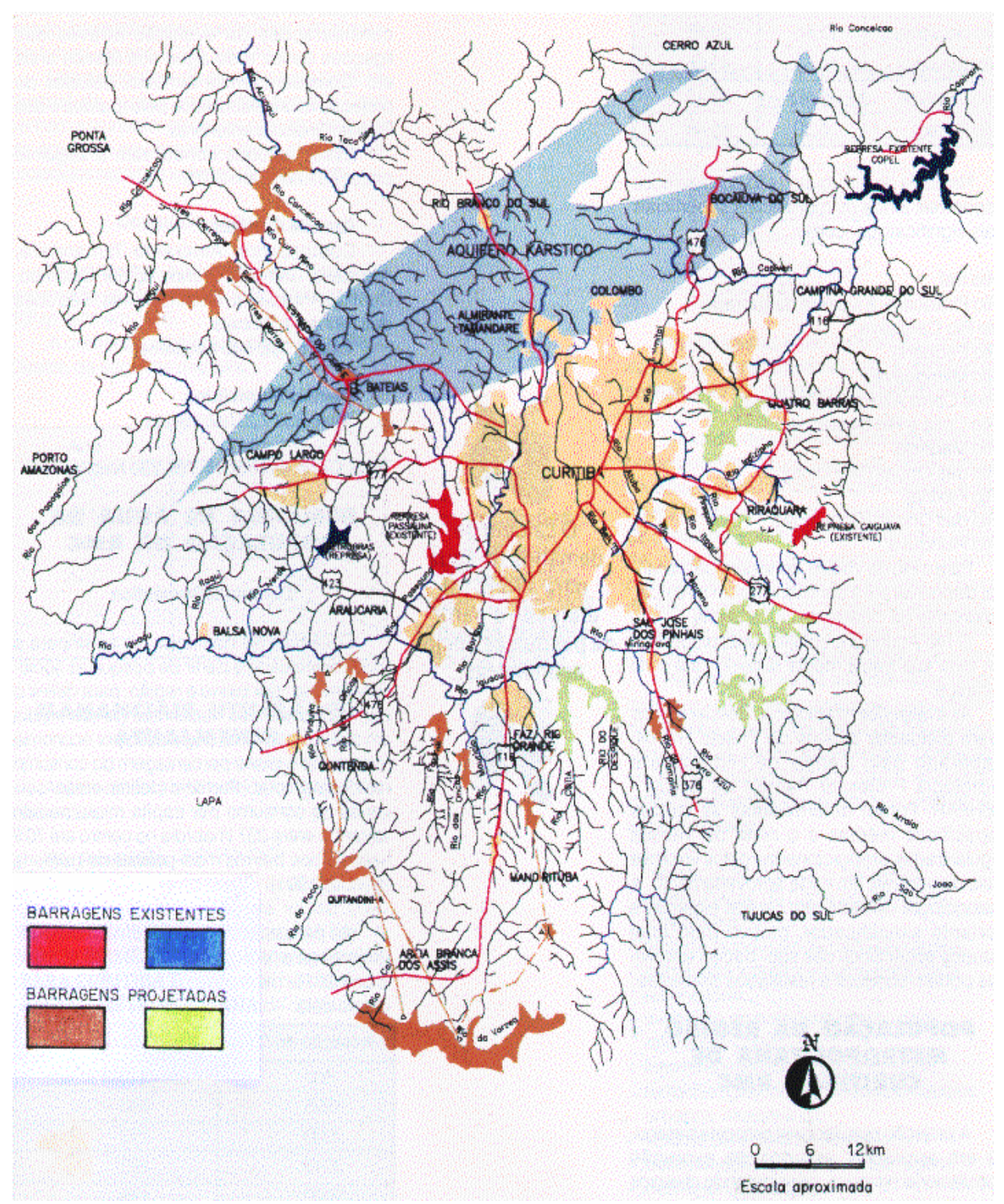

Fig. 1.: Mapa com distribuição das barragens existentes e projetadas (DALARMI, 1995).

O banco de dados da SUDERHSA e os cadastros de poços das empresas Acquasul, Tecnopoços, Kupersul e Hidropoços, até o ano de 1995, totalizavam aproximadamente 1.500 poços. Esses poços produzem em média $4.000 \mathrm{~L} / \mathrm{h}$ e são utilizados, na maioria dos casos, para atender condomínios, hospitais e postos de serviços em geral. Existem 24 localidades que são abastecidas com águas do embasamento cristalino. A média populacional dessas localidades é de 3.285 pessoas, sendo que a menor é habitada por 250 pessoas e a maior com aproximadamente 35.950 habitantes. O número total de habitantes que são abastecidos com águas do aqüífero embasamento cristalino é de aproximadamente 76.285 pessoas, o que corresponde a 7.189 ligações. Considerando uma taxa média de bombeamento dos poços de $16 \mathrm{~h} /$ dia, o volume extraído por ano é cerca de $549.234 \mathrm{~m}^{3} / a n o$. Acrescentando ainda os 1.500 poços utilizados por vários condomínios e postos de serviços da RMC, com uma taxa média de bombeamento de mais ou menos 10 h/dia, explota-se desse aqüífero mais $5.184 .000 \mathrm{~m}^{3} / a n o$. O volume explotado através dos dois grupos de poços, da SANEPAR e privados, é da ordem de $5.733 .234 \mathrm{~m}^{3}$ /ano.

Em termos de qualidade, as águas dos migmatitos não apresentam restrições para o consumo humano. Elas são classificadas como bicarbonatadas cálcio-magnesianas e contém teores de sólidos totais dissolvidos entre 100 e $150 \mathrm{mg} / \mathrm{L}$, pH entre 6,5 a 7,2 e dureza inferior a $100 \mathrm{mg} / \mathrm{L}$ de $\mathrm{CaCO}_{3}$. Entre os cátions, predominam o cálcio (2 a 20 
$\mathrm{mg} / \mathrm{L})$ e o magnésio $(0,5$ a $12 \mathrm{mg} / \mathrm{L})$ em relação ao sódio (1 a $3 \mathrm{mg} / \mathrm{L}$ ) e ao potássio (1 a 2 mg/L).

\subsection{Aquífero Cárstico}

O aqüífero cárstico da RMC, igualmente localizado no Primeiro Planalto Paranaense, está representado por mármores calcíticos e dolomíticos que ocorrem segundo faixas contínuas de extensão lateral de $15 \mathrm{~km}$, associados a filitos e quartzitos numa seqüência diferencialmente dobrada da Formação Capiru (BIGARELLA, 1948). As estruturas carstificadas desenvolvidas nas rochas carbonáticas distribuem-se preferencialmente até os $150 \mathrm{~m}$ de profundidade. A vazão média dos poços perfurados nas rochas carbonatadascarstificadas é de aproximadamente 160.000 $\mathrm{L} / \mathrm{h}$ ou $44 \mathrm{~L} / \mathrm{s}$, sendo que os valores de capacidade específica variam de $20 \mathrm{~L} / \mathrm{h} / \mathrm{m}$ a $100.000 \mathrm{~L} / \mathrm{h} / \mathrm{m}$. (FONTANA; LISBOA, informaçao verbal).

A população atualmente abastecida com águas do aqüífero cárstico gira em torno de 185.515 habitantes, sendo que aproximadamente 84.000 deste total reside na cidade de Curitiba. Excetuando-se as cidades de Almirante Tamandaré e Colombo, cuja população aproximada é de 93.000 pessoas, as demais localidades apresentam uma média populacional de 324 pessoas. O total de ligações atinge 20.302 unidades. A taxa média de bombeamento dos poços gira em torno de $16 \mathrm{~h} / \mathrm{dia}$, o que corresponde a um volume explotado da ordem de $9.028 .153 \mathrm{~m}^{3} / \mathrm{ano}$.

As águas do aqüífero cárstico são de ótima qualidade para o consumo humano. Trata-se de águas classificadas como bicarbonatadas cálcio-magnesianas cujo teor médio de cálcio é igual a $27 \mathrm{mg} / \mathrm{L}$, de magnésio $14 \mathrm{mg} / \mathrm{L}$, de sódio $1,0 \mathrm{mg} / \mathrm{L}$ e de potássio $0,99 \mathrm{mg} / \mathrm{L}$. Entre os ânions, o teor médio de bicarbonato gira em torno de 181 $\mathrm{mg} / \mathrm{L}$, de sulfato $3,8 \mathrm{mg} / \mathrm{L}$ e de cloreto 1,7 $\mathrm{mg} / \mathrm{L}$. De acordo com BONACIM (1996), a dureza total $\left(\mathrm{CaCO}_{3}\right)$ varia de $104 \mathrm{mg} / \mathrm{L}$ a $262 \mathrm{mg} / \mathrm{L}$ e segundo a classificação de SZIKSZAY (1993), tais valores enquadram este tipo de água como mediamente a bastante duras. $\mathrm{O} \mathrm{pH}$ varia 7,1 a 8,6 , sendo a média em torno de 8,2.

\subsection{Aqüífero Guabirotuba}

O aqüífero Guabirotuba é representado por lentes de areias arcoseanas que ocorrem intercaladas nos sedimentos pelíticos da bacia de Curitiba (argilitos e siltitos). Este pacote sedimentar cuja espessura máxima atinge $80 \mathrm{~m}$ ocupa uma área de aproximadamente $400 \mathrm{~km}^{2}$ na RMC. A Formação Guabirotuba foi sedimentada num ambiente de leques aluvionares coalescentes, bem como num sistema de drenagem entrelaçado ao lado de extensas playas (BECKER, 1982).

A vazão média dos poços perfurados na parte central da bacia de Curitiba, onde a distribuição das lentes de arcóseos é significativamente irregular, é da ordem de $5.000 \mathrm{~L} / \mathrm{h}$. Na região nordeste da cidade de Curitiba, especificamente na área de abrangência da bacia hidrográfica do Iraí, os arenitos arcoseanos ocorrem próximos do contato com o embasamento cristalino sob a forma de camadas contínuas, com espessuras que variam de 4 a $15 \mathrm{~m}$. Alguns dos poços que seccionaram essas camadas produzem vazões de até $80.000 \mathrm{~L} / \mathrm{h}$. O índice pluviométrico da RMC é da ordem de 1.500 mm/ano. Estima-se que as camadas aqüíferas do Guabirotuba, nesta região, tenham capacidade para produzir até 2.160 $\mathrm{m}^{3} / \mathrm{h}$ o que, num regime de $16 \mathrm{~h} / \mathrm{dia}$ de bombeamento, representa uma produção de aproximadamente $12.600 .000 \mathrm{~m}^{3} /$ ano. Com este volume, é possível abastecer uma população de mais ou menos 172.800 pessoas.

As águas do aqüífero Guabirotuba, em algumas áreas, apresentam teores de ferro que variam entre 0,05 a $5 \mathrm{mg} / \mathrm{L}$ e de manganês, que atingem valores de até 1,5 $\mathrm{mg} / \mathrm{L}$. A concentração média de sólidos totais dissolvidos é da ordem de $150 \mathrm{mg} / \mathrm{L}$, a dureza total varia de 30 a $230 \mathrm{mg} / \mathrm{L}$ de $\mathrm{CaCO}_{3}$ e o $\mathrm{pH}$ varia entre 6,8 a 8,1. A concentração de bicarbonatos atinge valores de até $195 \mathrm{mg} / \mathrm{L}$, a de sulfato varia de 1,2 a $4,5 \mathrm{mg} / \mathrm{L}$ e a de cloretos gira em torno de $2 \mathrm{mg} / \mathrm{L}$. Predominam os teores de cálcio até $30 \mathrm{mg} / \mathrm{L}$, sendo que o magnésio varia entre 8 a $15 \mathrm{mg} / \mathrm{L}$, o sódio entre 18 a $24 \mathrm{mg} / \mathrm{L}$ e o potássio entre 1,2 a 2,3 $\mathrm{mg} / \mathrm{L}$.

\subsection{Aqüífero Aluvionar}

Os sedimentos aluvionares que merecem destaque sob o ponto de vista hidrogeológico são representados pelas camadas de areias e de cascalhos existentes na calha do rio Iguaçu. Os sedimentos aluvionares do rio Pequeno, afluente do Iguaçu, possuem até $5 \mathrm{~m}$ de espessura e 
armazenam um volume de água igual a 4.048.335 $\mathrm{m}^{3}$ (ROCHA, 1996). Esta mesma autora menciona que de uma única cava com dimensão de $320 \mathrm{~m} \times 80 \mathrm{~m} \times 2,5 \mathrm{~m}$, cujo volume armazenado é alimentado por águas oriundas do freático, foram extraídos aproximadamente $360.000 \mathrm{~L} / \mathrm{h}$. Após 24 horas de bombeamento, o rebaixamento resultante foi igual a 0,41 m. Embora estes resultados sejam indicativos de que esses sedimentos representem excelentes reservatórios de água, os mesmos, lamentavelmente, não são reconhecidos como tal. Não se cogita, por esta razão, a possibilidade de preservar essas áreas para o aproveitamento do seu potencial hídrico.

\section{Quadro Resumo da População} Abastecida com Águas Subterrâneas na RMC

A população aproximada abastecida com águas subterrâneas na RMC e o volume anual aproximado produzido pelos poços tubulares profundos perfurados até 0 ano 1996, são apresentados a seguir.

\begin{tabular}{c|c|c}
\hline Aqüífero & $\begin{array}{c}\text { Pop. } \\
\text { Abastecida }\end{array}$ & $\begin{array}{c}\text { Volume } \\
\text { prod. } \\
\text { ( } \mathbf{m}^{3} \text { /ano) }\end{array}$ \\
\hline Cristalino & 76000 & 5733234 \\
Cárstico & 185515 & 9028153 \\
Guabirotuba & 178800 & 12600000 \\
\hline Total & 434315 & 27361367 \\
\hline
\end{tabular}

\section{Conclusões}

O índice pluviométrico anual da RMC, da ordem de $1500 \mathrm{~mm}$, e a média das vazões dos poços tubulares do aqüífero cárstico, de $260000 \mathrm{~L} / \mathrm{h}$, do embasamento cristalino, de $4000 \mathrm{~L} / \mathrm{h}$, e das camadas aqüíferas da Formação Guabirotuba, de $5.000 \mathrm{~L} / \mathrm{h}$, demonstram a importância das águas subterrâneas para o abastecimento público de Curitiba. Portanto, não faz mais sentido fixar a priori e intransigentemente que somente os rios e as barragens são as soluções definitivas para resolver os problemas de falta de água de Curitiba. As análises para a definição de sistemas de abastecimento público devem contemplar, imprescindivelmente, aspectos técnicos, econômicos e ambientais dos recursos hídricos disponíveis.

\section{Referências Bibliográficas}

BECKER, R. D. (1982). Distribuição dos sedimentos cenozóicos da região metropolitana de Curitiba e sua relação com a estrutura geológica e morfológica regional. Tese de doutorado. UFRS, p 237. Porto Alegre.

OECD-Organization for economic cooperation and development. (1989). Water resources management-integrated policies. p 199. Paris.

REBOUÇAS, A. C. (1980). Estágio atual dos conhecimentos sobre águas subterrâneas do Brasil. Rev. Águas Subterrâneas. ABAS, 2(1): 1-10

REBOUÇAS, A. C. (1996). Diagnóstico do setor de hidrogeologia. Caderno técnico da Associação Brasileira de Águas Subterrâneas - ABAS. 46 p. São Paulo-SP.

ROCHA, A. E. (1996). Hidrogeologia da Bacia Hidrográfica do Rio Pequeno. Tese de mestrado. UFPR. 156 p. Curitiba.

SOLLEY, W. B.; PIERCE, R. R.; PERLMAN, H. A. (1993). Estimated use of water in the United States in 1990. U.S. Survey, Circular 1081.

SZIKSZAY (1993). Geoquímica das águas. Boletim IG-USP, sér. didático, 5:1-166. São Paulo. 